\title{
Response
}

\section{Health Care: Multi-Payer or Single-Payer?}

Dhaval Dave

Bentley University \& National Bureau of Economic Research (NBER), 175 Forest St., AAC 195, Waltham, MA 02452, USA.

E-mail: ddave@bentley.edu

Eastern Economic Journal (2017) 43, 180-182. doi:10.1057/s41302-016-0085-7; published online 25 October 2016

With the U.S. spending more on health care than any other developed nation and yet achieving lower levels of health (ranking 28th, in terms of life expectancy at birth, among the 35 OECD countries, for instance), it is evident that our health care system is ailing. David Collander's thought-provoking article "Reforming the Affordable Care Act" (ACA) rightfully diagnoses what ails U.S. health care, underscoring the central problems related to cost and accessibility. The issue that David points to is that accessibility and health care costs are strongly intertwined - the high cost of medical care raises insurance premiums making it difficult for many to afford coverage and obtain access to quality care. While I agree with this assessment, David overlooks the reverse feedback (from the uninsured or under-insured to higher costs) and downplays the importance of the "insurance problem." Certainly, as health care costs rise, more people - many younger, and for the moment in good health - opt to live without insurance, which raises rates for everyone else. However, there is evidence that uninsured individuals end up costing the health care system more, not just from the standpoint of administrative expenses or because of their lower bargaining ability as David notes, but because they lack a routine source of care. For instance, those who were previously uninsured received fewer basic clinical services when uninsured and, upon gaining Medicare coverage, cost the program an additional $\$ 1,000$ annually per person when compared to those who were consistently covered. ${ }^{1}$ These increased costs were mainly due to delayed care and preventable hospitalizations. Lack of insurance, which leads to such fragmented care, is thus at least partly responsible for the inefficient care; when we look at life expectancy at age 65, the age at which Medicare provides virtually universal care in the U.S., health disparities between the U.S. and other developed nations substantially narrow.

The primary aim of the ACA has been to improve accessibility, and it does so by reforming the non-group insurance market. To the extent that almost 20 million individuals have newly gained coverage as a result of it, this would lead to a more efficient allocation of resources between preventive and curative care and reduce costs over time. Nevertheless, almost 30 million individuals still lack coverage. And, for political reasons the ACA was not able to fully take on cost control, instead including a variety of promising proposals which may or may not be successful in bending the cost curve. I agree with David that holding down health care costs is key to addressing the accessibility problem as well, but the $\$ 3$ trillion question is how. 
The U.S. system currently is a hybrid between a single-payer and a multi-payer system, and David proposes the fair health care pricing and health insurance pricing laws to move the system in the direction of a true multi-payer system. Both are laudable and based on sound economic principles, the first being motivated by efficiency gains from blocking the use of bargaining/monopsony power and the second motivated by efficiency gains from experience-rated health care premiums. However, in undercutting a movement in the reverse direction toward a single-payer model, which could be facilitated, for instance, by reinstating the "public option" into the ACA to create a government-run health insurance agency that would compete with other private companies on the insurance exchanges, David's proposal may leave substantial cost savings on the table or even exacerbate some inefficiencies. A relatively large degree of administrative cost pervades our system precisely due to the existence of multiple payers. The average U.S. physician spends 43 minutes daily interacting with insurance plans and hires staff to support billing functions. ${ }^{2}$ As much as $\$ 361$ billion annually (14\% of total health care costs) is spent on health care administration, though this figure masks considerable heterogeneity across private plan administration and Medicare administration. ${ }^{3}$ The U.S. version of the single-payer model, Medicare, spends only about $2 \%$ of its operating expenditure on administrative costs, compared to about $17 \%$ of revenues for the private insurance industry. While the fair health care pricing law may reallocate overhead, in maintaining the current multiplicity of policies and payers and related bureaucracy however, it would not substantially reduce the level of the overhead.

David addresses the very important issue of how to draw young and healthy individuals into the insurance market, which has been a challenge facing the insurance exchanges under the ACA. Experience-rated insurance premiums, which reflect an individual's health status and the actuarial cost of covering that individual, would indeed be an efficient form of pricing and lower premiums for the young and healthy (in contrast to community-rated premiums which are more or less independent of health status). However, this would price many individuals out of the market - for instance, those with chronic conditions or preexisting conditions - and thus require subsidies which would be in direct proportion to one's health status or risk. (Currently, under the ACA, subsidies are related only to income and not to health status.) Linking subsidies to health and risk would not moderate the incentives for ex ante moral hazard - the notion that insurance may increase unhealthy behaviors if the health costs of such behaviors are not reflected in the pricing, as would be the case if unhealthy individuals are receiving the larger subsidies. Granted that these incentives are also strong under community rating, the point relates to the tradeoff between moderating these incentives and pricing high-risk individuals out of the market, in turn reducing accessibility for groups with the strongest need. Furthermore, insurance pricing differentials between the individual, small group and large group markets prior to the ACA, in states which allowed experience-rated premiums, reflected not just differences in risk levels, but also differences in monopsony power, pooling, scale economies, and administration costs, which would continue to exist under the fair insurance pricing law as proposed.

David concludes with the essential point that the reforms he outlines (and those brought about by the ACA) are not sufficient. Cost control in the health care system ultimately has to address how we deliver care and the embedded payment incentives, which currently are mostly based on quantity and volume rather than quality and performance. I am not sure however that a multi-payer system would be most amenable to new models of organizing and reimbursing medical providers. On the contrary, such reforms are intrinsically more likely under a single-payer system. As Jon Gruber notes, cutting health care costs in the U.S. would mean cutting incomes for the medical sector, 
which is never politically easy and would be even more difficult under a multi-payer system.

If we had to design a health care system from scratch, our current hybrid model would likely not have been the outcome. The question then is whether to adopt reforms that move this model toward a true multi-payer system or a single-payer system (for instance, by incorporating a public option into the ACA and adopting payment reforms). While it is difficult to point to such frictionless multi-payer systems currently in existence for evidence, there are single-payer systems (including Medicare in the U.S.) which we can look to for favorable evidence regarding accessibility and cost.

\section{Notes}

1. See McWilliams et al. [2009].

2. Cutler et al. [2012].

3. Yong [2010].

\section{References}

Cutler, D., E. Wikler, and P. Basch. 2012. Reducing Administrative Costs and Improving the Health Care System, New England Journal of Medicine, 367: 1875-1878.

McWilliams, J.M., E. Meara, A.M. Zaslavsky, and J.Z. Ayanian. 2009. Medicare Spending for Previously Uninsured Adults. Annals of Internal Medicine, 151: 757-766.

Yong, P.L., R.S. Saunders, and L. Olsen eds. 2010. The Healthcare Imperative: Lowering Costs and Improving Outcomes-Workshop Series Summary. Washington, DC: National Academies Press. 